\title{
A Novel Method of Auxiliary Power Supply Used in Wide-Range High Voltage Input DC-DC Converter
}

\author{
Jie Zhang, Liangjie Li, Cuicui Liu \\ Hubei Collaborative Innovation Center for High-Efficiency Utilization of Solar Energy, \\ Hubei University of Technology, Wuhan, China \\ Email: 452388356@qq.com
}

How to cite this paper: Zhang, J., Li, L.J. and Liu, C.C. (2017) A Novel Method of Auxiliary Power Supply Used in WideRange High Voltage Input DC-DC Converter. Energy and Power Engineering, 9, 703-712.

https://doi.org/10.4236/epe.2017.94B076

Received: March 15, 2017

Accepted: March 30, 2017

Published: April 6, 2017

\begin{abstract}
In high voltage input DC-DC converter, auxiliary winding of isolation transformer is usually used to supply power for control circuit. Due to the widerange of input voltage, the variable output voltage of auxiliary winding will cause a series of problems, such as variable drive pulse amplitude, increased driver switching devices loss and drive transformer core saturation. This paper analyzes the influence of variable output voltage of auxiliary winding in detail. A novel method is proposed to solve the problem of large variation range of auxiliary winding output voltage, which is adding a buck converter between the auxiliary winding and the control circuit. A dual switch forward convert has been designed with $300 \mathrm{~V}-800 \mathrm{~V}$ input and $24 \mathrm{~V} / 5$ A output. The results show that this method is effective by comparing the different results of using buck converter or not.
\end{abstract}

\section{Keywords}

Dual Switch Forward Converter, Wide-Range Input, Auxiliary

Winding of Power Supply, Buck Converter

\section{Introduction}

Among various kinds of inverters, due to the different output voltage, the $\mathrm{dc}$ voltage changes in a relatively wide range. Double transistor forward DC/DC converter with its good isolation performance, resistance of straight bridge arm, low switch stress of power components is widely used for high input voltage. Therefore, in all kinds of inverters, double transistor forward converter is the common solution for auxiliary power of inverter.

Double transistor forward converter with high and wide range input voltage is 
widely researched home and abroad. In literature [1], the duty ratio of a novel resonant reset asymmetrical dual-switch forward converter is increased to more than $50 \%$.

However, the rang of input voltage is very narrow. Literature [2] use two-level $\mathrm{DC} / \mathrm{DC}$ converter for the solution to solve the problems for wide range input voltage in special military vehicle system. That double transistor forward circuit and double Buck Boost circuit cascade is only applicable from $85 \mathrm{~V}$ to $450 \mathrm{~V}$, and the drive control is complex. In literature [3], the double transistor forward auxiliary power with high and wide range input voltage whose equivalent circuit model of drive is established because of the characteristics of no external power supply, high frequency and high voltage isolation, and low latency. Literature [4] uses driver chip with time-sharing self power supply technology to drive the bridge arm, which can simplify the drive circuit, and solve the feedback problem of two-transistor Fly back circuit, develop an auxiliary power supply prototype whose input voltage ranges of $80 \mathrm{~V}$ to $800 \mathrm{~V}$, and $24 \mathrm{~V}$ output voltage. Literature [5] designs an auxiliary power whose starting branch can be automatically disconnected after working, input voltage ranges between $300 \mathrm{~V}$ and $2500 \mathrm{~V}$, and $24 \mathrm{~V}$ output voltage. Above literature research two-Transistor Forward converter with high and wide range input voltage in the operation mode, connection mode, drive circuit, feedback and starting circuit respectively, but haven't found the effect of auxiliary winding. Therefore, in order to guarantee the stability of the power supply, researching the power supply of two-Transistor Forward converter with high and wide range input voltage is of great significance.

Double transistor forward and Flyback converter with high and wide range input voltage have the problem of unstable power supply of auxiliary winding. Unstable power supply will cause the design of the power supply of control chip, the drive circuit, the isolation transformer harder, has a great influence on the efficiency and temperature rise of converter. Stable power supply way is the key to guarantee the normal operation of double transistor forward converter with high and wide range input voltage.

\section{Power Supply Way of Auxiliary Winding for Two-Transistor forward Converter}

In this paper, the principle of double transistor forward converter based on peak current-model control mode is presented.

UC3845 is selected as controller, a double transistor forward converter is developed whose input voltage ranges between $300 \mathrm{~V}$ and $800 \mathrm{~V}, 24 \mathrm{~V}$ output voltage and 5 A output current.

\subsection{Power Supply of Chip Starting}

The startup current of UC3845 is $2 \mathrm{~mA}$, which is supplied by the DC bus voltage through partial pressure resistance. The resistance is $100 \mathrm{k} \Omega$. The startup current is between $2.85 \mathrm{~mA}$ and $7.86 \mathrm{~mA}$.

The design of Power supply circuit for chip starting is shown in Figure 1. 


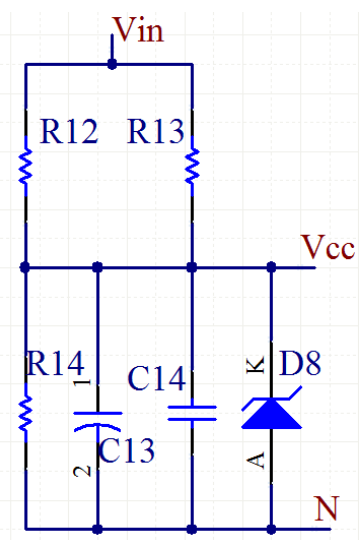

Figure 1. Power supply circuit of chip starting.

Equation is the startup current calculated formula of UC3845:

$$
I=\frac{V_{\text {in }}-V_{C C}}{R}
$$

When the power supply in the minimum input voltage $\mathrm{V}_{\text {in-min }}=300 \mathrm{~V}$, the resistances R12 and R13 is in parallel, which is cascaded with R14, then $\mathrm{V}_{\mathrm{CC}}=8.5$ $\mathrm{V}$. When $\mathrm{V}_{\text {in }}>675 \mathrm{~V}$, the zener diode starts work, so $\mathrm{V}_{\mathrm{CC}}=18 \mathrm{~V}$.

\subsection{The Power Supply of Auxiliary Winding}

If the control circuit was supplied only by the starting circuit, the power supply capacity is serious short. By reducing current limiting resistor to improve the power supply capacity, it is equivalent to a linear power supply, which will cause huge loss of power supply circuit. To reduce power loss and improve the efficiency of power supply, the control circuit is supplied through integrating a fly back transformer auxiliary winding.

\subsection{Design of Drive Circuit}

Double tube driver needs two isolation drive pulse. Transformer has strong drive, simple structure, strong reliability, strong anti-jamming capability, and good insulation effect. This paper adopts transformer isolation drive mode. Drive circuit selects the topology of three windings demagnetization and the two lines of output. The deliverypoint is the input of isolation transformer. The drive circuit is shown in Figure 2.

\section{Analysis of Power Supply Problem of Traditional Auxiliary Winding}

\subsection{Calculation of Supply Voltage for Traditional Auxiliary Power Supply}

Auxiliary winding adopts flyback power supply method, and winding port voltage depends on the voltage transformer primary side and the control chip work duty cycle.

Equation (2) is flyback converter ratios calculated formula: 


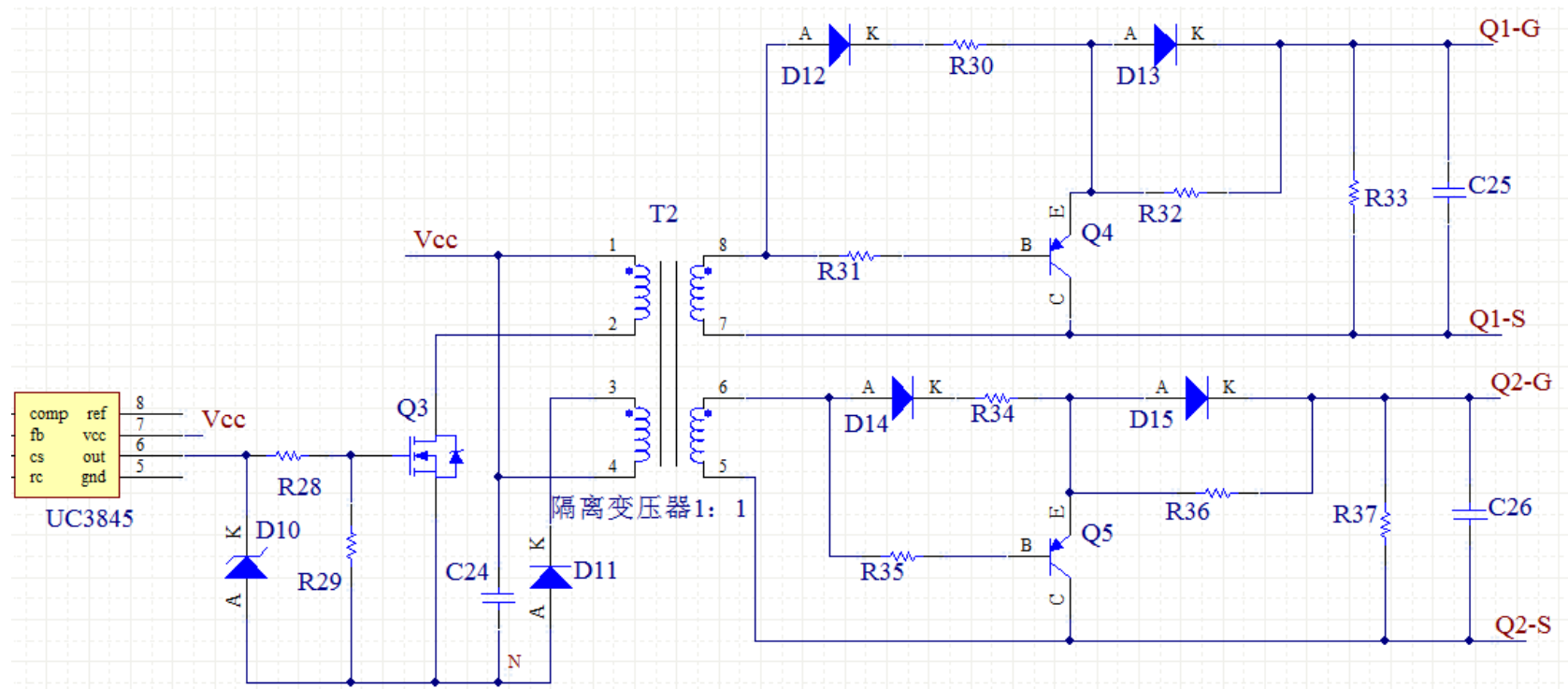

Figure 2. Drive circuit.

$$
n=\frac{U_{\text {in }} * D}{U_{s} *(1-D)}
$$

Among them: $U_{\text {in }}$ as the input voltage; Us for winding voltage; $D$ for duty cycle.

In order to ensure that the $\mathrm{V}_{\mathrm{CC}}$ meet the requirements of power supply at any time, we take $\mathrm{U}_{\text {in-min }}=300 \mathrm{~V}, \mathrm{U}_{\mathrm{S}}=8.5 \mathrm{~V}, \mathrm{D}_{\max }=0.5$ to the Formula (2).

$\mathrm{N}=35.2$.

When $U_{\text {in-max }}=800 \mathrm{~V}$, the maximum voltage of the auxiliary winding is $U_{\text {smax }}$.

$$
U_{s \max }=U_{s \min } * \frac{U_{i n \max }}{U_{i n \min }}=22.6 \mathrm{~V}
$$

The secondary winding of the power supply voltage range is $8.5 \mathrm{~V}-22.6 \mathrm{~V}$.

\subsection{Analysis of Traditional Auxiliary Power Supply}

Power supply instability has three effects on circuit design.

\subsubsection{The Impact on the Trigger Pulse Amplitude}

UC3845 control chip output is a push-pull circuit structure and its internal structure is shown in Figure 3. The OUTPUT pulse voltage is decided by the supply port $\mathrm{V}_{\mathrm{CC}}$. When the trigger pulse is low, OUTPUT port is connected to ground, $\mathrm{V}_{\mathrm{DS}}=1 \mathrm{~V}$, then OUTPUT port voltage is $1 \mathrm{~V}$. When the trigger pulse is high, the power supply port voltage $\mathrm{V}_{\mathrm{CC}}$ drop $\mathrm{V}_{\mathrm{DS}}$, then output.

\subsubsection{The Impact on Isolation Transformer}

Isolation transformer is a fixed ratio, and the main circuit switch is selected SCT240KEC that gate and drain voltage $\mathrm{V}_{\mathrm{GSS}}$ is limited between- $6 \mathrm{~V}$ and $22 \mathrm{~V}$ and the threshold voltage is limited between $1.6 \mathrm{~V}$ and $4 \mathrm{~V}$. Transformer variable ratio selected 1: 1: 1: 1. Isolation transformer core is EE25, which material is ferrite PC40. Taking the natural cooling mode into account, magnetic flux swing 


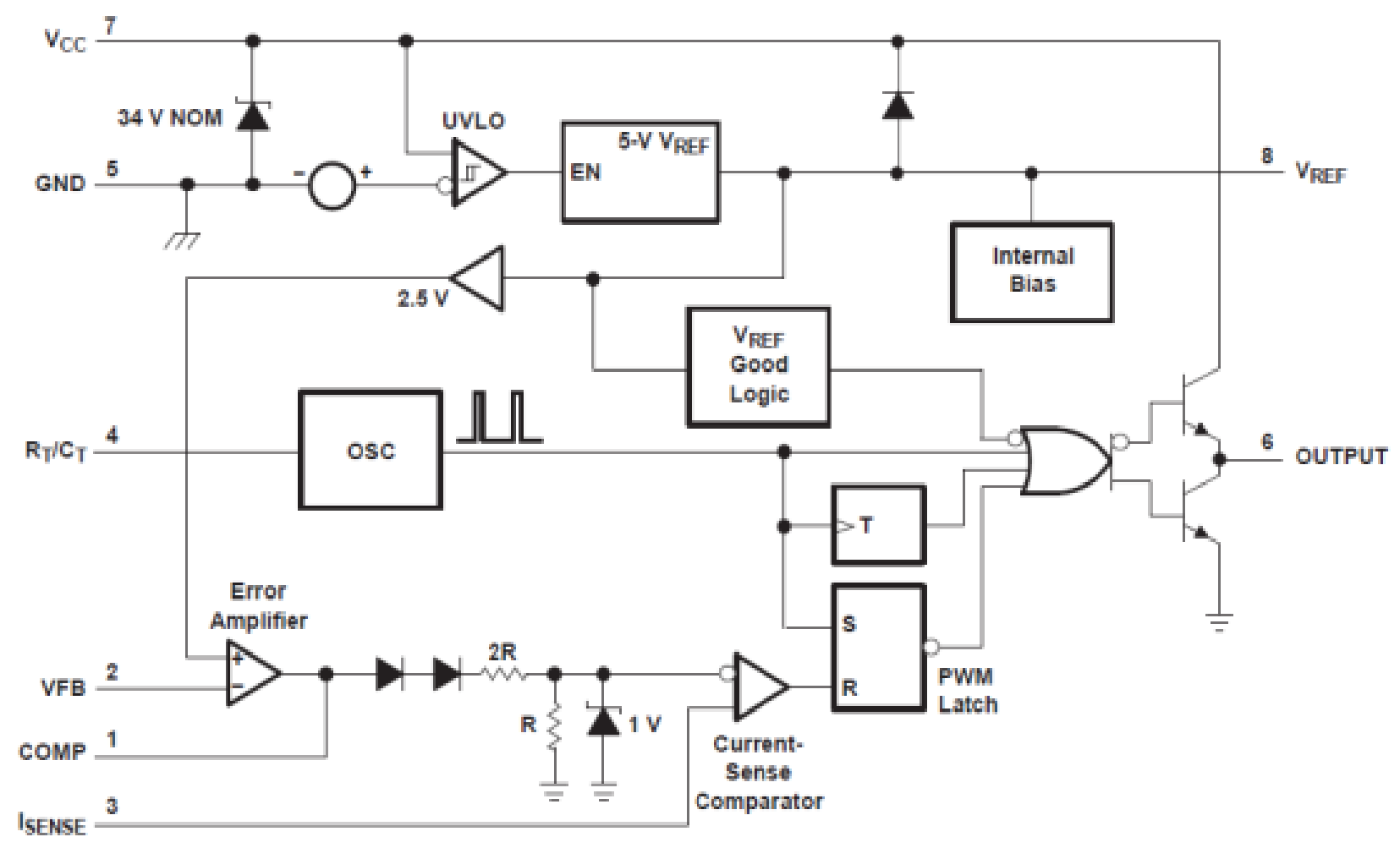

Figure 3. UC3845 internal structure.

amplitude $\Delta \mathrm{B}$ take $0.2 \mathrm{~T}$, and isolation transformer inductance $\mathrm{L}_{\mathrm{P}}$ value is 1.5 $\mathrm{mT}$.

Equation (3) is the relationship between the input voltage of the forward converter and the swing of the flux density calculated formula:

$$
U_{i}=N_{1} A_{\mathrm{e}} \frac{\Delta B}{T_{\mathrm{on}}}
$$

Among them: $\mathrm{U}_{\mathrm{i}}$-transformer primary voltage $(\mathrm{V}) ; \mathrm{N}_{1}$-the primary turns of the transformer; $A_{\mathrm{e}}$-core effective cross-sectional area $\left(\mathrm{m}^{2}\right) ; \Delta \mathrm{B}$-magnetic flux density swing (T); Ton-conduction time (s).

When transformer design is completed, $\mathrm{N}_{1}$ and $\mathrm{A}_{e}$ is a fixed value, $\mathrm{T}_{\text {on }}$ is controlled by a control chip, which will not affect the magnetic flux density swing in the drive circuit. So the transformer is directly proportional to the input voltage $\mathrm{V}_{\mathrm{CC}}$ and $\Delta \mathrm{B}$. if the $\mathrm{V}_{\mathrm{CC}}$ changes from $8.5 \mathrm{~V}$ to $22.6 \mathrm{~V}$, the maximum magnetic flux density swing range is $0.2 \mathrm{~T}$ to $0.53 \mathrm{~T}$, which will exceed the saturation magnetic flux density of the ferrite core material 0.5. The experimental phenomenon is that with the $\mathrm{V}_{\mathrm{CC}}$ rise, resulting in transformer copper consumption increases, the transformer temperature rising will be correspondingly increased, resulting in magnetic flux density saturation point down. When $\mathrm{V}_{\mathrm{CC}}$ voltage is up to $18 \mathrm{~V}$, current is nonlinear growth, rising sharply, transformer saturation, and winding voltage waveform distortion with much higher harmonic components that can make higher maximum potential. Temperature rising sharply rise will damage the transformer and switch tube. 


\subsubsection{The Impact on the Driver Switch Tube}

According to the design requirements, it selects the switching drive for the IRF530N. $\mathrm{V}_{\text {GSS }}$ is limited between- $20 \mathrm{~V}$ and $20 \mathrm{~V}$. Gate-to-Source voltage is $2 \mathrm{~V}$ $4 \mathrm{~V}$, and on-resistance is $0.6 \Omega$. Gate drive circuit is designed to use a $15 \mathrm{~V}$ zener diode IN4746. When $\mathrm{V}_{\mathrm{CC}}$ is greater than $16 \mathrm{~V}$, Zener diode began to work, so the UC3845 pulse amplitude is $15 \mathrm{~V}$, resulting in huge loss of drive circuit.

Equation (4) is peak driving circuit current and input voltage calculated formula:

$$
I_{\mathrm{p}}=\frac{P_{0}}{\eta D_{\max } * V_{S}}
$$

Among them : $\mathrm{P}_{0}$ is driving power $(2 \mathrm{~W}), \eta$ is a converter conversion efficiency $(0.85), \mathrm{D}_{\max }$ is maximum duty cycle $(0.5), \mathrm{V}_{S}$ is the isolation transformer input voltage.

Equation (5) is the effective value of the current calculated formula:

$$
I=I_{P} \sqrt{D}
$$

When $\mathrm{V}_{\mathrm{S}}$ changes from $8.5 \mathrm{~V}$ to $22.6 \mathrm{~V}$, the variation range of $\mathrm{I}_{\mathrm{P}}$ is $69.4 \mathrm{~mA}$ $208 \mathrm{~mA}$.

Equation (6) is the conduction loss of the switch tube calculated formula:

$$
P_{\mathrm{on}}=I^{2} R_{\mathrm{on}}=I_{P}^{2} D R_{\mathrm{on}}
$$

When $\mathrm{I}_{\mathrm{P}}$ changes in $69.4 \mathrm{~mA}-208 \mathrm{~mA}$, the highest current conduction loss is 7.1 times of the minimum power consumption.

\section{The Solution of the Auxiliary Winding Power Supply}

\subsection{The Way to Solve the Problem of Traditional Power Auxiliary Winding}

By the analysis of the problems existing in the traditional auxiliary winding shows that wide range input voltage can produce very big fluctuation voltage range on the auxiliary winding port. Auxiliary winding power supply instability is the source of the pulse voltage amplitude changes, drive switch damage and isolation transformer saturation. Therefore, the auxiliary winding power supply using a stable supply voltage scheme is the key to solve the problem. There are three ways to provide voltage regulator: zenerdiode, linear power supply, switching power supply.

Zenerdiode: the maximum regulated current of the zener diode is only ten to several tens of milliamps, and the low power regulator is usually about a few hundred milliwatts to several watts. That is not adapted to the need for a larger current.

Linear power supply: the adjust tube work in the linear amplification area, so the load when circuit the current is large. The adjust the collector loss is quite large, power consumption and efficiency is relatively low.

Switching power supply: the adjust tube work in saturated conduction and cut-off state, so it has low power consumption, high efficiency, small size, light 
weight, and wide voltage range.

Taking the volume and efficiency into consideration, the choice of switching power supply the method. Auxiliary winding voltage range $8.5 \mathrm{~V}$ to $22.6 \mathrm{~V}$, and control chip of operating voltage is $8.2 \mathrm{~V}$. Buck converter regulator can achieve auxiliary winding power supply voltage stability

\subsection{The Auxiliary Winding Stable Power Supply Program}

To solve the wide range input control part of the power supply voltage instability problems, this paper presents a scheme to supply the buck circuit to the auxiliary winding power supply. Wide range of high-voltage input double transistor forward converter auxiliary winding power supply is shown in Figure 4.

The imr16006 integrated control chip control buck circuit is shown in Figure 5. When the buck circuit applied to auxiliary winding, winding voltage convert the $V_{C C}$ port voltage to $9 \mathrm{~V} / 2 \mathrm{~W}$. Not only can it eliminate the drive switch gate drive overpass voltage problem, but also prevent the drive transformer core from saturation and temperature rising. Buck circuit integrated module size is: length + width + height $<30 \mathrm{~mm}$.

\section{Experiment and Result Analysis}

This experiment have achieved a double transistor forward converter that input voltage is $300 \mathrm{~V}$ to $800 \mathrm{~V}$, and output voltage is $24 \mathrm{~V} / 5 \mathrm{~A}$. The traditional winding

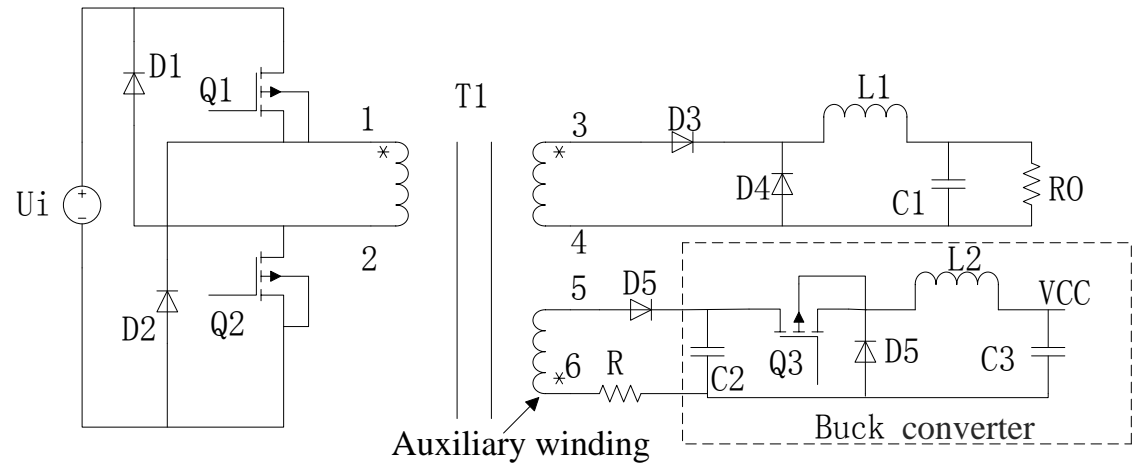

Figure 4. Auxiliary winding power supply diagram.

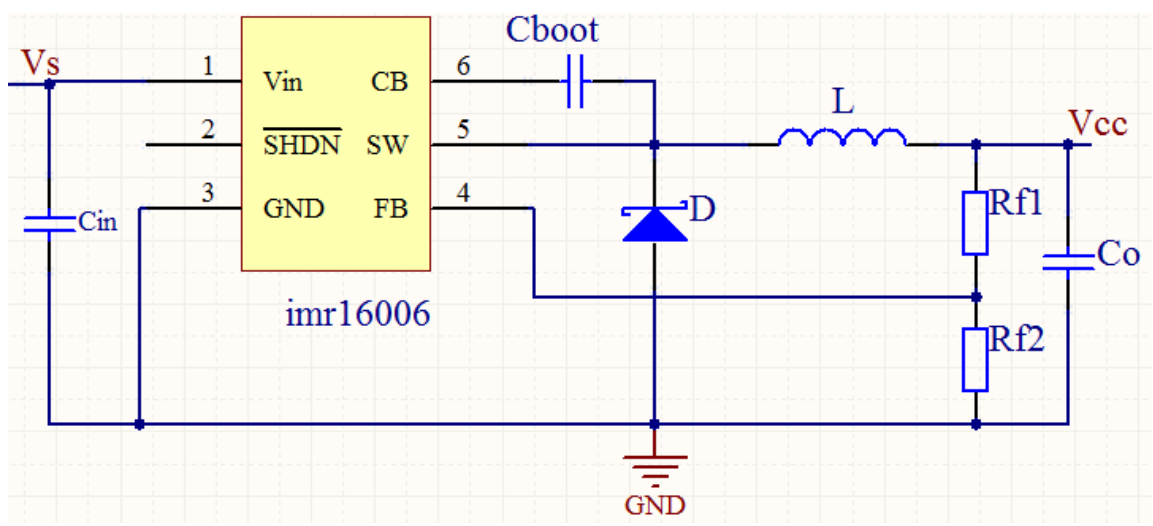

Figure 5. Buck circuit schematic diagram. 
power supply and the program's experimental waveform were recorded on. When the input voltage is $305 \mathrm{~V}, 360 \mathrm{~V}, 601 \mathrm{~V}$ respectively, the traditional winding power supply $\mathrm{V}_{\mathrm{CC}}$ waveform are as shown in Figures 6-8.

The input voltage $V_{\text {in }}$ corresponds to the size of the auxiliary winding supply port $\mathrm{V}_{\mathrm{CC}}$, switching drive temperature rising $\mathrm{T}_{1}\left({ }^{\circ} \mathrm{C}\right)$ and isolation transformer temperature rising $\mathrm{T}_{2}\left({ }^{\circ} \mathrm{C}\right)$ is shown in Table 1 . The room temperature is $20^{\circ} \mathrm{C}$.

From the experimental waveform and recorded temperature rising results show that: with the input voltage increases, the auxiliary winding to provide the supply voltage $\mathrm{V}_{\mathrm{CC}}$ is increase, and temperature rising of drive switch and isolation transformer are also rise. When the voltage reaches $650 \mathrm{~V}$, the core of the isolation transformer is saturated and the current grows nonlinearly, and the temperature rising exceeds $80^{\circ} \mathrm{C}$ within $10 \mathrm{~s}$.

When the buck circuit is applied to the auxiliary winding, the experimental waveform about the power supply $\mathrm{V}_{\mathrm{CC}}$ are shown in Figures 9-11.

The figure shows: buck circuit does not work, when the power supply port below $9 \mathrm{~V}$. If the power supply port is higher than $9 \mathrm{~V}$, the buck circuit make the power supply stabilize at $9 \mathrm{~V}$, so the drive switch and isolation transformer temperature rising is basically unchanged at $30^{\circ} \mathrm{C}$.

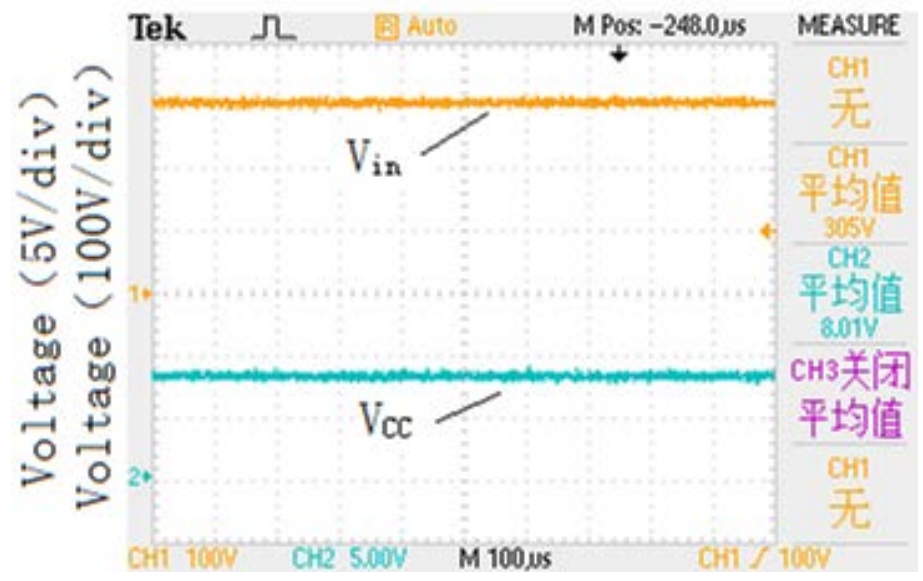

Figure 6. $\mathrm{V}_{\text {in }}$ and $\mathrm{V}_{\mathrm{CC}}$ voltage waveform at $305 \mathrm{~V}$.

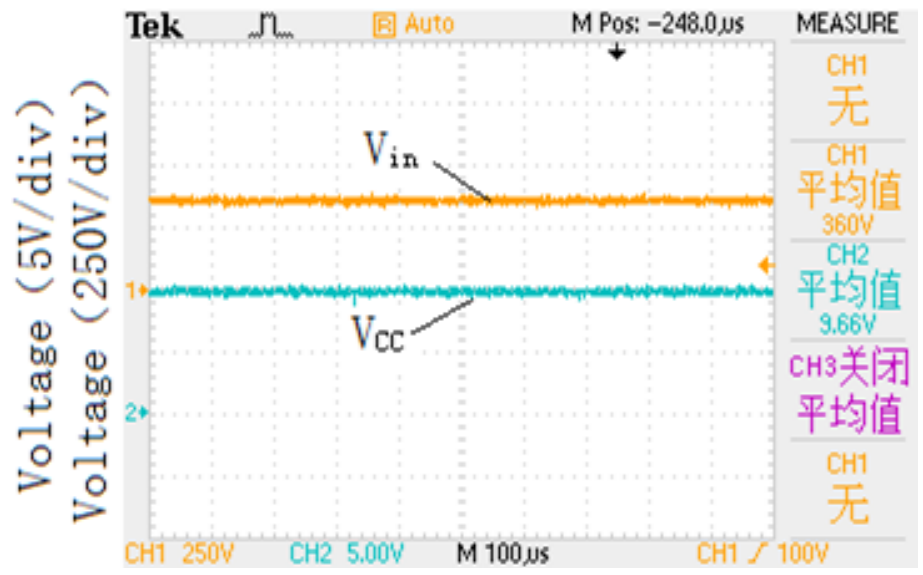

Figure $7 . \mathrm{V}_{\text {in }}$ and $\mathrm{V}_{\mathrm{CC}}$ voltage waveform at $360 \mathrm{~V}$. 


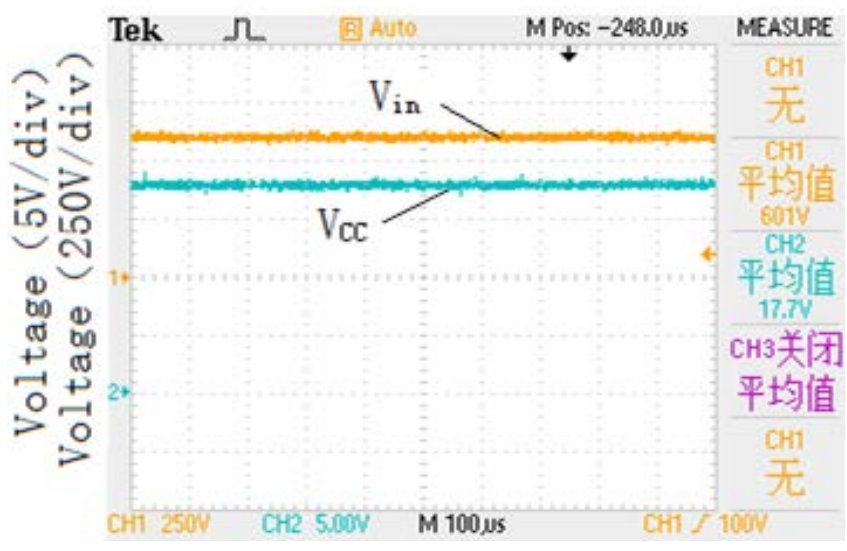

Figure 8. $V_{\text {in }}$ and $V_{C C}$ voltage waveform at $601 \mathrm{~V}$.

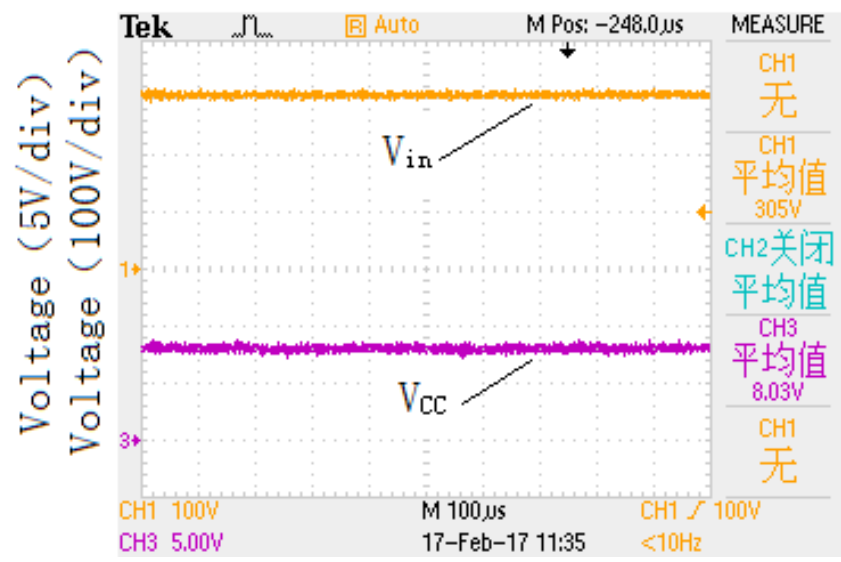

Figure 9. $\mathrm{V}_{\text {in }}$ and $\mathrm{V}_{\mathrm{CC}}$ voltage waveform at $305 \mathrm{~V}$.

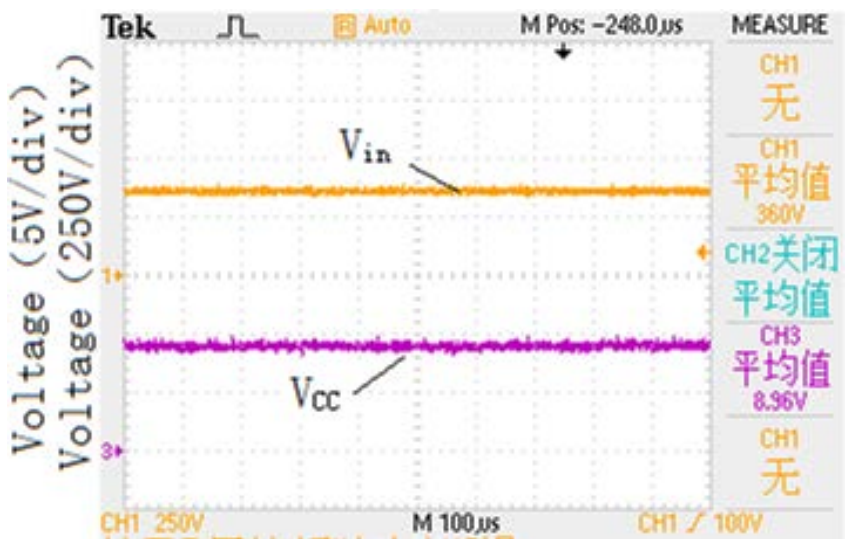

Figure 10. $\mathrm{V}_{\text {in }}$ and $\mathrm{V}_{\mathrm{CC}}$ voltage waveform at $360 \mathrm{~V}$.

Table 1. The result of experiment.

\begin{tabular}{rcccccc}
\hline $\mathrm{V}_{\text {in }}(\mathrm{V})$ & 300 & 400 & 500 & 600 & 700 & 800 \\
$\mathrm{~V}_{\mathrm{CC}}(\mathrm{V})$ & 8 & 10.7 & 13.8 & 17.7 & 18.8 & 22.6 \\
$\Delta \mathrm{T}_{1}\left({ }^{\circ} \mathrm{C}\right)$ & 5 & 12 & 26 & 48 & 56 & 70 \\
$\Delta \mathrm{T}_{2}\left({ }^{\circ} \mathrm{C}\right)$ & 3 & 11 & 23 & 52 & - & - \\
\hline
\end{tabular}

Note: "-" in Table 1 indicates that the temperature rising exceeds $80^{\circ} \mathrm{C}$. 


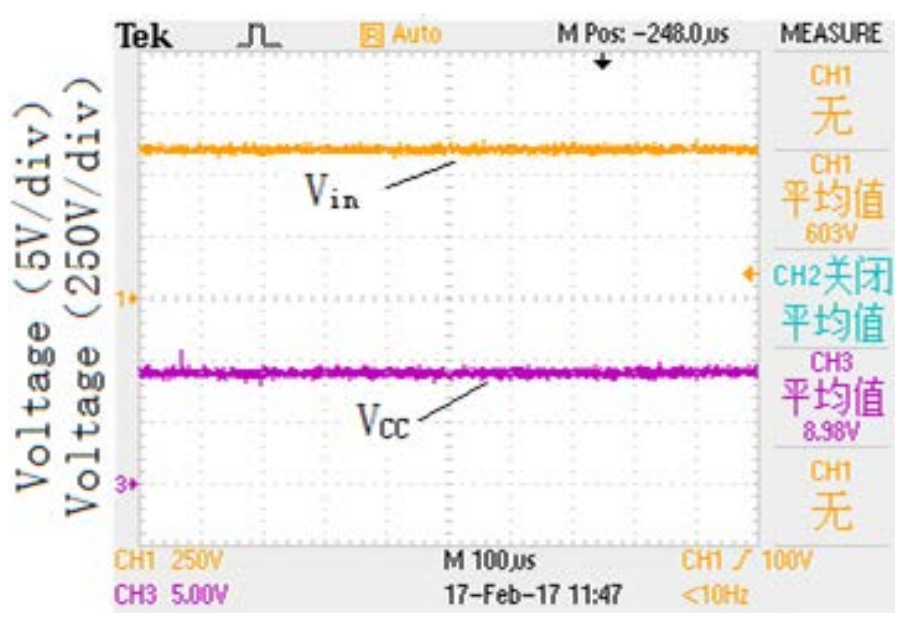

Figure 11. $\mathrm{V}_{\text {in }}$ and $\mathrm{V}_{\mathrm{CC}}$ voltage waveform at $601 \mathrm{~V}$.

\section{Conclusion}

In this paper, a wide range input voltage of the double transistor forward power supply using auxiliary winding power supply, the traditional auxiliary power supply problems are analyzed and improved. If there is a buck circuit in the auxiliary winding, it can achieve auxiliary winding power supply voltage stability; this scheme can avoid the selection of the main power switch limited by the gate drive voltage threshold, the saturation of the isolation transformer, and improve the stability of the drive circuit, which is suitable for wide-range input of low power DC-DC converter.

\section{References}

[1] Gu, X.M. (2005) Study on a Wide Range Dual-Forward Forward DC / DC Converter. Journal of China Electromechanical Engineering, 25, 44-48.

[2] Yu, P.(2011)Study on Wide Range Input Two-Stage DC / DC converter. Chongqing University.

[3] Hu, L.D., Zhao, Z.H., Sun, C., et al. (2015) Study on Driving of High-Voltage Input Double-Tube Flyback Assisted Power Supply. Journal of Electrotechnical Society, 30,161-170. https://doi.org/10.1149/2.0451504jes

[4] Chen, D.P., Sun, C., Ai, S., etc. (2014) A Wide Range of Dual-Tube Flyback DC / DC Auxiliary Power Supply Design. Power Technology, 11, 2125-2129.

[5] Hu, L., Sun, C., Zhao, Z.H., et al. (2015) Design of DC-DC Auxiliary Power Supply with High Voltage and Wide Range Input Low Voltage Output. Journal of Electrical Engineering, 2, 103-114. 
Submit or recommend next manuscript to SCIRP and we will provide best service for you:

Accepting pre-submission inquiries through Email, Facebook, LinkedIn, Twitter, etc. A wide selection of journals (inclusive of 9 subjects, more than 200 journals)

Providing 24-hour high-quality service

User-friendly online submission system

Fair and swift peer-review system

Efficient typesetting and proofreading procedure

Display of the result of downloads and visits, as well as the number of cited articles Maximum dissemination of your research work

Submit your manuscript at: http://papersubmission.scirp.org/

Or contact epe@scirp.org 